\title{
INTRA-OCULAR PRESSURE IN THE DONOR EYE AND CONSEQUENT SHAPE OF CORNEAL DISC MARGIN* $\dagger$
}

\author{
BY \\ BASDEO SWARUP AND ERIC C. COWAN \\ Royal Victoria Hospital, Belfast
}

IN over 100 corneal grafts carried out in this clinic from 1960 to 1966, it was found that the edges of the donor discs varied in shape when observed from the side, and these variations were of sufficient clinical importance to determine the success of the results, the best grafts being those with clean-cut straight edges. These observations led us to seek a procedure whereby the desired shape of the donor graft edge could be ensured. Barraquer Moner (1955) noted irregularities of the graft edge and suggested that another disc should be cut if the first was uneven.

Pierse (1959) noted that, even with the sharpest trephine, the corneal curvature would be flattened while the disc was being cut, and that this produced a trephine hole in which the edges shelved inwards. He found that a lower intra-ocular pressure in the donor eye produced an even greater shelving and while an increased intra-ocular pressure produced by pressure on the outside of the eye resulted in straight sides. He tried to maintain the shape of the cornea while cutting a donor disc by using the plunger of the trephine as a suction cup.

Michaelson (1954) found that the sides of a corneal graft were vertical if it was cut from the endothelial surface, or when the donor eye was held with a firm pressure. He did not specify the equal distortion produced by too much as well as by too little pressure.

Gorgiladze (1960a) suggested that the best donor disc was got by using Filatov's method of withdrawing the fluid from the anterior chamber before cutting the graft, and again cutting from the epithelial surface. He later (1960b) concluded that cutting from the endothelial surface had no advantages, but stated that the best disc edges were got with an intra-ocular pressure of $50-60 \mathrm{~mm}$. $\mathrm{Hg}$; pressures of 8-15 mm. $\mathrm{Hg}$ gave edges bevelled towards the inside, and a pressure as high as $200 \mathrm{~mm}$. $\mathrm{Hg}$ again distorted the edges.

\section{Present Investigations}

The intra-ocular pressure in experimental pigs eyes was maintained at a definite level while the disc was cut with a trephine. This allowed flattening of the cornea within certain ranges.

Material

The following items were required: Pigs eye, "T" tube, cannula for eye, syringe, manometer with inch scale, rubber tubing, $6 \mathrm{~mm}$. trephine, normal saline.

\section{Method}

Eyes from 4-months-old pigs slaughtered at Belfast Abattoir were collected and kept in a domestic refrigerator for 3 hours before the experiments were conducted. To facilitate the variations in intra-ocular

- Received for publication December 5, 1966

† Address for reprints: Eye Clinic, Royal Victoria Hospital, Belfast. 
pressure, the vitreous humour was replaced with normal saline. A cannula was connected to one of the horizontal limbs of a "T" tube and the manometer to the other end by rubber tubing. The vertical limb of the " $T$ " tube was connected to a syringe (Fig. 1), and the system was filled with saline. The cannula was inserted into the eye, and the tension was noted on an inch scale attached to the free limb of the manometer. While the disc was being cut, the intra-ocular pressure was regulated within a definite range by means of the syringe on the " $T$ " tube. The discs were cut at six different ranges of intra-ocular pressure maintained at $5^{\prime \prime}, 10-14^{\prime \prime}, 15-19^{\prime \prime}, 20-25^{\prime \prime}, 35-40^{\prime \prime}$, and 45-50".

Eight eyes in each range were used for cutting the discs with a $6 \mathrm{~mm}$. trephine. The discs were cut transversely at the diameter and the two ends of each cut edge were examined with an operating microscope. The shapes were of a definite conformation for a definite series of intra-ocular pressures (Fig. 2).

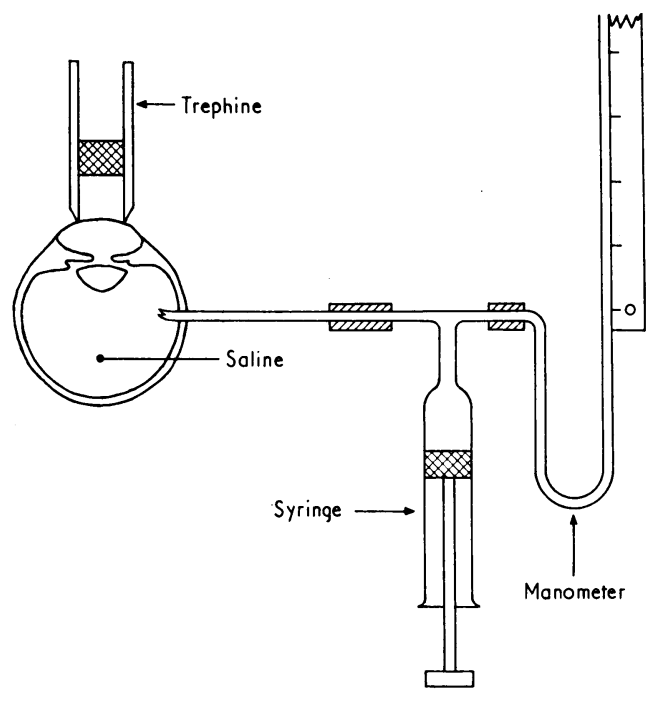

Fig. 1.- Apparatus.

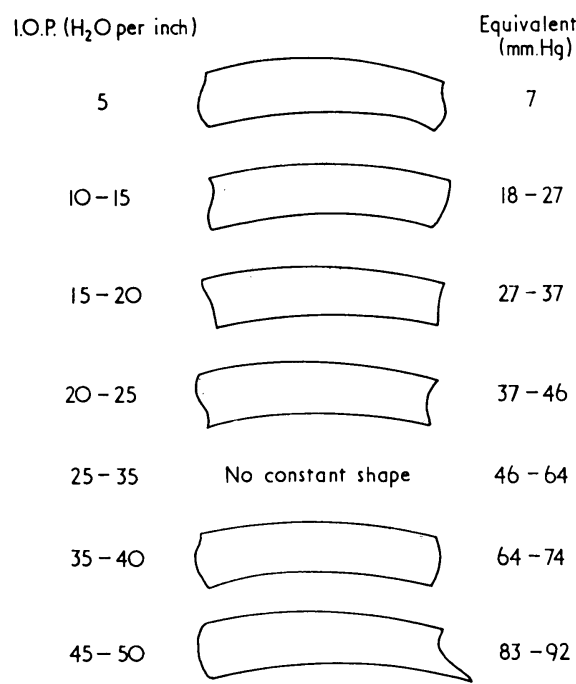

FIG. 2.- Conformation of disc edges related to intra-ocular pressure.

\section{Discussion}

Four factors influence the conformation of the disc:

(1) The sharpness of the corneal trephine.

(2) Corneal rigidity.

(3) Pressure applied by the surgeon.

(4) Intra-ocular pressure in the donor eye.

The trephines used were sharp and the eyes used were of the same age and offered the same rigidity. The remaining variable factors were the intra-ocular pressure in the donor eye while the disc was cut and the pressure exerted by the surgeon in cutting the graft. Thus the resultant ocular tension as measured by the manometer was equal to the sum of the intra-ocular pressure, the pressure due to the weight of the trephine, and the pressure exerted by the surgeon. This tension was maintained in each case with the help of the syringe attached to the system throughout the process of cutting the disc. 


\section{Results}

The best disc margins were obtained at a pressure of 27 to $37 \mathrm{~mm}$. Hg. This demonstrated that the intra-ocular pressure in the donor eye acted in three ways:

(1) It kept the cornea in its proper shape and prevented shelving.

(2) It helped in cutting the deeper final stages cleanly and without leaving tags of tissue due to the rotation of the disc with the trephine.

(3) It increased the cutting effect of the trephine by holding up the corneal disc firmly against it.

We are grateful to the late Sir Benjamin Rycroft for his interest and advice in our work, and to Mr. J. R. Wheeler for allowing us to operate on his patients. The Medical and Education Research Grants Committee of the Northern Ireland Hospitals Authority have been most liberal in their financial support.

\section{REFERENCES}

Barraquer Moner, J. I. (1955). "Full-thickness Grafts", in "Corneal Grafts", ed. B. W. Rycroft, p. 106 (pp. 86-111). Butterẉorths, London.

Gorgiladze, T. U. (1960a). Ophtal Zh., No. 1, p. 27.

(1960b). Ibid., No. 3, p. 160.

Michaelson, I. C. (1954). Brit. J. Ophthal., 38, 19.

PIERSE, D. (1959). Trans. ophthal. Soc. U.K., 79, 203. 